\title{
The impact of innovative smart design solutions on achieving sustainable interior design
}

\author{
W. Rashdan \\ College of Design, Al Ghurair University, UAE
}

\begin{abstract}
The recent decade has witnessed a rapid evolution of technology, global communications, and networking. These technological manifestations paved the way for smart interior design solutions, and stimulated the environment for designers studying the effect of integrating smart solutions into aspects of sustainable interior design. This pragmatic approach found a considerable positive impact on enhancing overall building sustainability. On a larger scale, this design method will save global resources and create healthy, beneficial, and comfortable environments; moreover, it supports the progression of technological lifestyles. This paper is a review of the theoretical concepts behind smart design and sustainability, exploring the benefits of interior design solutions that incorporate smart technologies with various aspects of sustainability.

Keywords: interior design, smart technology, smart interior design, innovative smart design solutions, sustainability, sustainable interior design.
\end{abstract}

\section{Introduction}

The information revolution and the rapid evolution of technology were driving forces behind dramatic developments across all fields of research, including the construction industry [1]. This tremendous development has also reinforced advancements in computer integrated systems and control solutions. The resulting momentum of innovation opened up new opportunities and exciting solutions for smart building technology, an essential step toward establishing smart cities. Building management systems and the Internet of Things (IoT) make up the essence of smart design, and can be leveraged to effectively manage interior systems such as lighting, temperature, safety, and security. These systems provide 
data about buildings and user behaviour that can be analysed for the purpose of achieving more advanced integration systems, higher performances, and more efficient interior design solutions [2, 3]. Furthermore, building systems that utilize smart interior design solutions have the capability of learning and even anticipating occupants' needs and preferences, thereby optimizing dynamic processes, increasing lifestyle comfort and flexibility, raising energy efficiency, and reducing costs that lead to achieving a more sustainable interior design [4]. Smart design concepts can therefore be considered highly interrelated with sustainable design in support of creating a new environment that meets present needs without compromising future generations [5]. Hence, designers possessing the tools for on-going technology expansion realize that integrating smart solutions into interior design will significantly boost environmental, economic, and socio-cultural sustainability [6]. In other words, smart design offers increased suitability and futuristic vision to interior design, all while reducing humanity's carbon footprint. This paper aims to define smart interior design within the context of sustainability, emphasizing that integrating smart solutions into interior design will support designers in their pursuit of a more sustainable design.

\section{Smart interior design overview}

Since the late 20th century, building occupants' expectations of a more modern, flexible, and comfortable lifestyle have increased. Meanwhile, sophisticated technologies, artificial intelligence, and robotics have experienced great leaps in progress [7]. The emergence of the information revolution further influenced occupants' desire to make use of the internet, smart gadgets, web-enabled integration platforms, and IP-enabled devices in their daily lives. Technology has matured in its practicality and economic feasibility, owing to solid industry standards, increased market demand, and substantial cost reductions that made technology available to a greater number of people. These attributes also reinforced the expansion of building demographics toward embedding technology and network connectivity within their infrastructures, enabling smart buildings to become part of the mainstream [8]. Consequently, this stimulated interior designers to develop synergistic design concepts capable of integrating smart systems, fuelled by an increase in smart materials, smart devices, and sensors, as well as a wider coverage of internet connectivity and applications [9]. Smart buildings are thus structured on designs that accommodate adjustments for the convenience of occupants, while controlling resource consumption and studying occupants' behavioural patterns. In addition, smart buildings are characterized by their integrated communication and management systems which improve occupants' accessibility, security, and control over interior environments, and aim to increase productivity and user comfort levels [10].

\subsection{Smart interior design definitions}

Smart buildings were advocated in 1981 by United Technology Building Systems Corporation (UTBS) and became a reality in 1983 with the inauguration of the 
City Place Building in Hartford, Connecticut, USA [11, 12]. Since the early 1980s, several organizations have attempted to establish a definition for "intelligent" or "smart" buildings. These attempts resulted in a multitude of definitions, all with different levels of detail and varying degrees of emphasis on several aspects of the smart building [11].

The original definition, coined by the Intelligent Buildings Institute, defines a smart building as one which provides a productive and cost-effective environment through optimization of four basic elements: structure, systems, services and management, and the interrelationship between them to meet the occupants' needs with emphasis on the technological solutions [12].

The European Intelligent Buildings Group recommended a new definition stating that a smart building is based on design environment that maximizes the effectiveness of buildings while enabling efficient management of resources that results in minimizing life costs of facilities, tilting the spotlight towards the occupant's needs to be served by technology $[12,13]$.

Associations throughout Asia have generated many definitions, which all are essentially based on the following concept: a smart building is designed and constructed on the appropriate mapping of quality technological modules with building facilities to meet the user's requirements, hence achieving a long-termed building value $[14,15]$.

The most recent definition is based on the emergence of IoT technologies. That is, a smart design will overlay on IP network, online platforms, and databases that collect and analyse all the building services data without the intervention of humans $[13,16]$.

Based on previous definitions, smart interior design can be interpreted as a multi-faceted profession [17] in which creative and technical solutions should be integrated with smart material, furniture, devices, and sensors while all functions should be controlled and communicate together through IP network and mobile application with a reliable analysis system that is capable to respond quickly to occupants' requests and decide the most efficient way of providing a convenient, comfortable, safety and productive environment to enhance the quality of occupants lifestyle.

\subsection{Smart interior design characteristics}

Smart interior design is characterized by its ability to provide actionable information regarding the performance of design facilities; the design becomes a locus for receiving, transmitting, and analysing data. Smart interior design proactively monitors and detects errors or deficiencies within design systems, ensuring the satisfaction and convenience of the building's occupants [18]. It also contributes to resource rationalization, real-time reporting, and minimizing operational costs [9]. Smart interior design provides fast, flexible, and economic responses to the often diverse and complicated requests made by occupants, and determines the most efficient strategies for providing a convenient, comfortable, entertaining, and productive environment. 


\subsection{Smart interior design efficiency}

Efficiency of smart interior designs can be measured through four primary attributes.

The first attribute is integration. When smart interior design solutions are successfully integrated with the majority of design components, this will enhance performance, ease of operation, and minimize utility consumption over the design's life cycle [19].

The second attribute is the achievement of high communication facilitated by smart design. This includes person-to-person, person-to-machine, and machineto-machine communications, both within the interior environment and with the outside world, connecting buildings in a cloud network that serves as an essential part of smart cities $[9,10]$.

The third attribute is the capability to adapt easily to changes within the space and be flexible enough to accommodate new technology requirements $[18,19]$.

Finally, the fourth attribute that smart interior design should incorporate is control over building systems in order to optimize energy use while providing realtime and historical views of occupant behavioural patterns. Moreover, the use of smart materials and furnishings along with smart lighting and acoustic solutions helps occupants adapt to the interior design theme, thereby increasing occupant comfort and satisfaction $[12,18]$.

\subsection{Smart design facilities}

Smart design facilities include all available devices, sensors, transducers, signal conditioners, transmitters, converters, receivers, logic controllers, displays, recorders, and actuators. They also include network technologies, internet connections, and feature applications that serve the purpose of their modules [7]. Priority order will be set based on the developers', owners', and occupants' deliverable needs, as well as the building type, availability of funding, and the availability of system and service enabling technologies.

Smart interior design solutions should incorporate flexible structures that can accommodate smart design facilities. In particular, solutions should maintain responsive cabling design, an open space with movable or demountable partitions, raised floors, suspended ceilings, and mechanical floors to permit connection between different design elements across a single infrastructure, in addition to meeting the needs of future technologies $[7,12]$.

\subsection{Smart design systems}

The smart building has three types of systems, starting with the building automation system (BAS). The BAS includes a comprehensive collection of sensors and output devices that are intended to accomplish specific tasks and consist of elements providing a number of different functions. Sensors determine and control the performance of one or more interior climate systems such as temperature, relative humidity, pressure, ventilation, and air-conditioning. Output 
devices impart electronic signals or mechanical action to control devices such as relays, dampers, and valve actuators.

The second system of the smart building is an integrated system that creates centralized and simultaneous control over interior climate systems, in addition to lighting, security, fire suppression, and other such systems. This integrated system manages the local environment and controls energy usage.

The third system is the IoT system. Designers are increasingly installing IoT sensors into interior structures for the purpose of gathering data about movement, heat, light, and space usage [2]. Analysis of this information turns smart design into responsive, anticipatory, and personalized alterations to a building's environment in real-time, thus suiting its occupants and offering comprehensive usage tracking to manage resource consumption [20].

\section{Sustainable interior design}

Human evolution, due to our unlimited consumption of resources, has caused significant collateral damage to the natural environment, giving rise to major problems such as resource depletion, global warming, deforestation, and irresponsible urbanization [21]. These phenomena ushered in the advent of sustainability as an appropriate solution for the negative impact of our consumption on Earth. Sustainability is primarily concerned with saving the environment, reducing humanity's ecological footprint, and supporting economic growth in order to preserve our natural wealth.

Sustainable interior design can be defined as design that sensibly addresses the impact of all its functions and elements on the global environment. It can also be defined as a collection of concepts, systems, and materials that are integrated into design solutions for the purpose of reducing consumption and increasing the positive impact on social, economic, and environmental systems over a building's lifecycle $[17,22]$. Within the context of interior design, the most important goals of sustainability are to provide responsible environmental solutions that rely on minimal consumption of energy, maximal usage of renewable and local materials, and recycling natural resources, with respect to new design trends and technologies. Another goal of sustainable design is to provide healthy indoor environments by improving thermal comfort and reducing indoor pollutants [22]. A successful interior design project blends sustainability into each phase of the design process.

\section{Smart solutions for sustainable interior design}

The proliferation of smart design during the 2000s and its tendency to incorporate energy-efficient features led to a convergence with sustainability concepts [6]. This prompted several associations to consider smart design as a positive contribution toward sustainability. Both the Certification Policy Manual of the Leadership in Energy and Environmental Design (LEED) [23] and the Technical Manual of the Building Research Establishment's Environmental Assessment Method [24] include smart design solutions as part of evaluating a building's 
sustainability. Therefore, interior designers should understand the impact of applying smart solutions to sustainable interior design. Interior designers may consider this combination to be an ideal solution that reflects a concern for both natural ecological systems and building occupants' technological lifestyle [25].

Smart interior design is the future of design. It depends on the integration of varied sensors, devices, and computing into building systems through appropriate networking and operation platforms, as well as the innovative utilization of material, light fixtures, and equipment that support the expansion of sustainability practices. Smart design systems can effectively control and manage interior energy consumption and rationalize resource usage by monitoring and modifying lighting, thermal systems, ventilation, and water, thereby achieving operational efficiency and cost reductions $[1,6]$. Smart materials and furnishings dramatically reduce the need for different design components, sustaining the interior mood for longer periods. This trend also enhances the environmental and economic efficiency of interior design in addition to improving occupant wellbeing and productivity. The following sections explore the relation between smart solutions and major sustainable interior design domains (Figure1). These domains were selected based on criteria and measurements outlined in the LEED Certification Policy Manual for certifying a building as a sustainable project [23].

\subsection{Smart solutions for sustainable interior environments}

One of the ultimate goals of interior design is to offer a healthy, safe, and comfortable indoor environment. Smart design systems can be proactive in controlling air quality through the measurement of humidity, pollutants, and toxic gas emissions. Systems can reduce these undesirable particles through proper natural and mechanical ventilation [4]. This is achieved by controlling air pressure through HVAC systems and/or automation systems that open certain windows for natural ventilation. Smart design systems can also activate certain filters in mechanical ventilation systems, facilitating fresh air replacement and sustaining a high quality indoor air environment [26, 27].

In addition, there are several safety systems such as smart security systems, which help occupants monitor their property; fire alarm sensors; and evacuation guides. Interactive screens can be installed throughout the space to provide tips on increasing physical and mental wellbeing such as nutrition, sport and exercise, and psychological health, stimulating occupants' overall productivity and happiness [28].

\subsection{Smart solutions for interior consumption management}

Interior designers should encourage and recommend the use of smart systems by embedding them into their solution specifications, as well as showing their clients how these procedures will benefit all building stakeholders and their environment. Smart design can achieve efficient control over interior resource consumption through three main attributes.

Firstly, smart design systems rationalize interior resource consumption, using equipment such as those with stop and start controls, by monitoring space 
conditions and occupancy, then implementing sophisticated strategies for limiting energy use. For example, these strategies can restrict the operation of lighting systems and HVAC systems to the hours and areas of the building they are needed [26].

The second attribute lies in the smart design software, which can analyse information on consumption patterns, accurately determine occupants' lifestyle needs, anticipate required energy loads, and alert occupants of any irregular or heavy usage and suggest energy-efficient solutions [29]. Sensors and systems that monitor weather conditions can activate smart shading devices, providing suitable and consistent daylight throughout the interior space [30]. Usage patterns allow smart systems to manage and maintain interior temperature equilibrium to the occupants' satisfaction and comfort.

The third attribute is exclusively concerned with decreasing interior consumption. Embedding smart design systems into interior environments will vastly reduce consumption of a variety of resources. For instance, smart systems can activate cross-ventilation by creating negative air pressure through mechanical ventilation systems. Smart devices can also control hot water systems and adapt heating and cooling systems. A decrease in heating by one degree Celsius will provide annual energy savings of around 7\% [6, 29]. Utilizing smart appliances will also support energy efficiency. Interior designers should utilize smart sanitary equipment, such as water-efficient sinks and smart faucets, as well as smart irrigation systems to reduce water consumption [31]. Smart buildings can reduce energy consumption and carbon gas emissions by $50 \%$ and water usage by $30 \%$ $[6,29]$. Undoubtedly, this will help achieve sustainable interior designs that have a low impact on environmental resources. Designers can employ smart design systems that encourage the use of natural energy and minimize the need for nonrenewable resources, such as smart rainwater tanks. Another example is smart solar energy systems that embed solar power devices and adjustable solar panels into interior finishing material, allowing the system to gain maximum benefits from sun energy and manage a smooth transaction between stored energy and the regular electrical system.

The listed procedures demonstrate how smart design systems and technologies have contributed to the effective regulation of resource use and reduced energy consumption; this has a positive outcome on overall interior sustainability. Interior designers should work on embedding smart fixtures, fittings, and appliances into their design construction. This will produce responsible interior environments that reduce carbon emissions and save natural resources.

\subsection{Smart solutions for sustainable interior design construction}

Smart solutions for construction have a significant influence on supporting sustainable interior design and can be summarized with two items.

The first item is the utilization of smart software capable of speculating upcoming construction requirements, such as Building Information Modeling (BIM) software. BIM software was introduced as an information repository for sharing knowledge and resources on different design characteristics and functions. Hence, BIM software can establish good practices with different interior 
construction techniques and technologies that consider the natural features of the site, including topography, local climate, and cultural features. It also takes the future into account by minimizing the need for consequent modification. BIM software will help designers measure performance effectiveness and form a reliable basis for decisions made during the design lifecycle [14]. BIM software also guides designers toward choosing the best places for installing insulation materials, which play a crucial role in creating sustainable interior environments. The successful estimation of insulation placement can save up to 500 times more energy over the building's lifetime [32]. Hence, BIM software supports interior designers' decisions on the best methods of construction that reduce infrastructural and material waste, imparting a positive effect on construction time and cost as well as reducing negative impacts on the natural environment.

Secondly, smart construction technologies provide design with the dynamism required for differing functions; for instance, phase-changing pellets help control and maintain thermal environments in a building [33, 34]. Another example is mechanical interior design surfaces with transformation capabilities. These allow interior surfaces to support different functions, such as wall finishes and ceiling tiles that can change their form to enhance interior acoustics, or provide flexibility in smart lighting and materials to change design atmosphere.

\subsection{Impact of smart materials on sustainable interior design solutions}

Smart materials have one or more characteristics that can be significantly altered, such as form, colour, opacity, and viscosity, in response to one or more of the following stimuli: light, stress, temperature, moisture, and electric and magnetic fields [33]. There are a variety of smart materials that can be used in interior design such as self-acting and kinetic facades; wallpaper that changes its colour and pattern based on temperature and light; and smart paints and coatings characterized by their durable performance, property-changing, and energyexchanging materials [19]. Smart dichroic material exhibits colour changes to the viewer as a function of either the angle of incident light or the angle of the viewer [35]. Privacy film glass changes its appearance from transparent to opaque by rearranging its crystal molecule components through electrical currents, offering increased privacy for occupants [35]. Although, privacy film is not considered an energy-efficient material due to its electricity usage, it helps smart systems reduce long-term cooling and heating leakage without compromising natural light [19, 35].

Designers consider smart materials to be one of the most fascinating developments that help them achieve dynamic and innovative interior design solutions. Smart materials also dramatically enhance the environmental and economic efficiency of interior design. This is achieved by reducing the need for different design components and sustaining interior mood for longer periods due to the flexibility of smart materials to change design atmosphere. 


\subsection{Impact of smart furnishings on sustainable interior design solutions}

Furniture, fixtures, and equipment (FF\&E) are major elements of interior design. In the context of smart sustainability, selected furnishings should provide longterm use and utilize smart materials. Furnishings should also be fully integrated with the mood of smart devices and systems, and have flexible structural mechanisms that allow it to adapt to occupants' needs. Futuristic furnishings integrated with special technologies, possibly serving as multi-functional furnishings, are classified as innovative design solutions that conserve resources $[12,20]$.

The innovation potential of smart furnishings has infinite possibilities. Interior designers may utilize some of the available technologies such as interactive computer systems that provide valuable information to occupants and help them create their environmental mood using minimal resources; interactive touchsensitive OLED screens hidden under partitions that can change to match various moods; wall-sized displays that use cloud connectivity to project useful information across different rooms; smart kitchen countertops that can assemble a grocery list, suggest recipes based on refrigerator and pantry inventory; retail shop mirrors that give fashion advice; sensors that notify when plants need watering; and IoT technology-enabled surfaces that can create lifelike environments via the display of detailed, 360-degree images, enabling occupants to browse merchandise, hold conferences, or visit art galleries from their present location [28].

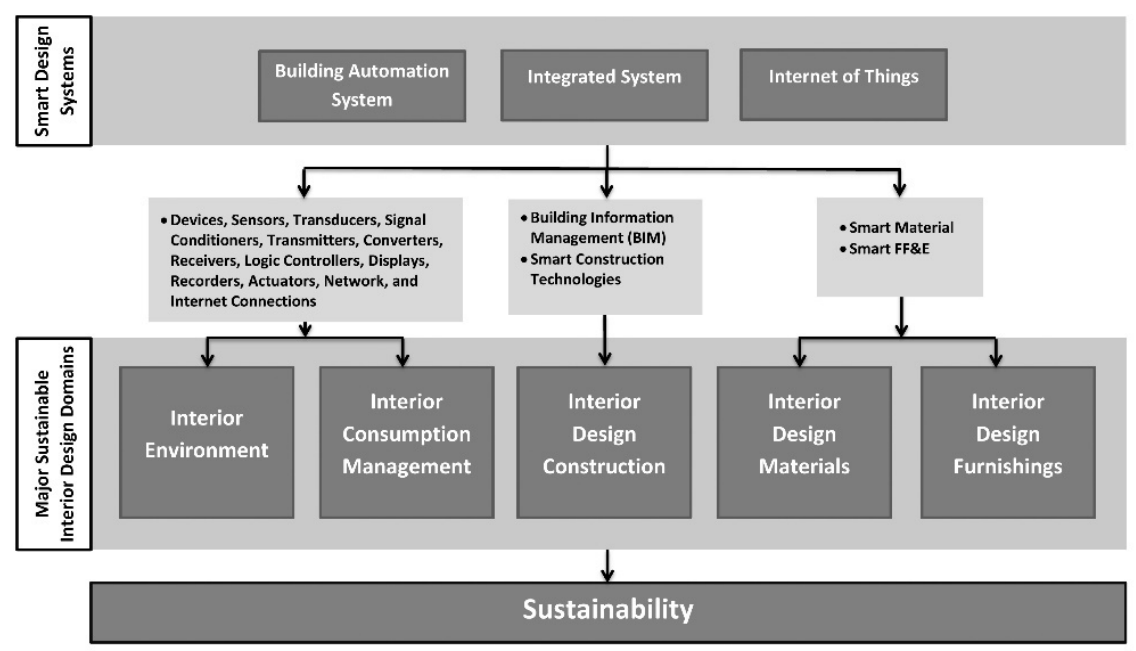

Figure 1: Smart solutions for sustainable interior design. 


\section{Conclusion}

A tremendous development in technology has unfortunately contributed to dramatically increasing problems such as global warming, resource depletion, deforestation, and irresponsible urbanization. On the other hand, this technology expansion has reinforced many advancements and innovations that, when used in cooperation with information technologies, can manage construction industry resources from the concept stage to demolition. In other words, we can use the results of technological development to mitigate the destruction of technology production.

This paper explored the relation between smart design and sustainable interior design. It showed that embedding smart technologies into interior design have a positive impact on aspects of sustainability, including environmental, economic, and socio-cultural sustainability.

Smart interior design has the potential to promote highly efficient spaces while significantly minimizing operating costs through accurate monitoring and intensive control of resource consumption, as well as facilitating renewable energy usage. Smart design solutions enrich occupants' comfort, safety, security, and sensory stimulation, and improve the overall health of interior environments. Employing smart materials and furnishings will give occupants the ability to change the interior mood, thereby extending the design's lifecycle. Thusly, smart design possesses an inherent relevance to principles of sustainability.

Smart design facilities and systems can control and store data for almost all elements in a building. This abundance of data should be identified and interpreted by designers in order to determine and understand occupants' behaviour patterns, which will contribute positively to predicting building usage and post-occupancy evaluations. Also, these systems can create a feedback loop that enhances future interior design construction through BIM software. This will encourage greater enthusiasm toward developing future smart interior designs with the ability to be proactive when making service changes on behalf of its users. Ultimately, smart design is not about gadgets and building data itself, but how we exploit the data to create better environments and services.

Smart designs are not a fad, but rather a technological progression with a huge future growth potential. Smart solutions should evolve and adapt to serve occupants' increasingly complex lifestyles. Therefore, designers should maintain positive communication with technology suppliers; such relationships will help them be aware of new technologies available and will feed manufacturers with information about the future technologies they need to develop. Collaboration between building stakeholders will eventually lead to more innovative and futuristic smart designs.

This study recommends that due to the dynamism of smart technology evolution, interior design researchers should consciously work toward studying, analysing, and evaluating the implementation of smart technologies within interior design, and emphasize its effective integration of sustainability practices. Thusly, this subject area warrants continual exploration. 


\section{References}

[1] Liu, K., Nakata, K., \& Harty, C., Pervasive informatics: theory, practice and future directions. Intelligent Buildings International, 2(1), pp. 5-19, 2010.

[2] RAENG, Smart buildings - people and performance report, Royal Academy of Engineering: London, 2013.

[3] Wacks, K.P., Best-Practices Guide for Evaluating Intelligent Building Technologies. Continental Automated Buildings Association: Ottawa 2002.

[4] ASHRAE, green guide: The design, construction, and operation of sustainable buildings, $3^{\text {rd }}$ Ed., American Society of Heating, Refrigerating, and Air-conditioning Engineers: USA, (2010).

[5] Wackernagel, M. \& Rees, W., Our ecological footprint: reducing human impact on earth, New Society Publishers: Gabriola Island, 1996.

[6] GhaffarianHoseini, A., Ibrahim, R., Baharuddin, M.N. \& GhaffarianHoseini, A., Creating green culturally responsive intelligent buildings: Socio-cultural and environmental influences. Intelligent Buildings International, 3(1), pp. 5-23, 2011.

[7] Wang, S., Intelligent Buildings and Building Automation, Routledge: NY, 2009.

[8] Clements-Croome, D., Intelligent Buildings: An Introduction, Routledge: New York, 2013.

[9] In Partnership with NJATC, Building Automation Integration with Open Protocols, Amer Technical Pub: California, 2009.

[10] Clements-Croome, D., Intelligent Buildings: Design, Management and Operation, $2^{\text {nd }}$ Ed., ICE Publishing: London, 2013.

[11] Atkin, B., Intelligent Buildings - Applications of IT and Building Automation to High Technology Construction Projects, Gower Publishing: UK (1993).

[12] So, A.T. \& Chan, W.L., Intelligent building systems, Springer: NY, 2012.

[13] GhaffarianHoseini, A., Berardi, U., AlWaer, H., Chang, S., Halawa, E., GhaffarianHoseini, A. \& Clements-Croome, D., What is an intelligent building? Analysis of recent interpretations from an international perspective. Architectural Science Review, pp. 1-20, 2015.

[14] Nikken Sekkei, Design with Real-time Analysis Reporting. Japan Architecture + Urbanism journal, Special Issue, 2009.

[15] So, A.T., Wong, A.C. \& Wong, K.C., A new definition of intelligent buildings for Asia. Facilities, 17(12/13), pp. 485-491, 1999.

[16] Memoori, The Transformation of BAS into the Building Internet of Things 2015 to 2020, Memoori Smart Building Research: London, 2015.

[17] IFI, International Federation of Interior Architects Designer, IFI Interiors Declaration Online. www.ifiworld.org

[18] In Partnership with NJATC, Building Automation: Control Devices and Applications, Amer Technical Pub: California, 2008.

[19] Sinopoli, J.M., Smart buildings systems for architects, owners and builders. Butterworth-Heinemann: USA, 2009. 
[20] Jang, W.S., Healy, W.M. \& Skibniewski, M.J., Wireless sensor networks as part of a web-based building environmental monitoring system. Automation in Construction, 17(6), pp. 729-736, 2008.

[21] Harris, F., Global Environmental Issues, $2^{\text {nd }}$ Ed., John Wiley \& Sons: New Jersey, 2012.

[22] Kang, M. \& Guerin, D.A., The state of environmentally sustainable interior design practice. American Journal of Environmental Sciences. 5(2), pp. 179-186, 2009.

[23] Leadership in Energy and Environmental Design, LEED Certification Policy Manual, US Green Building Council Online. www.usgbc.org

[24] BREEAM, Building Research Establishment Environmental Assessment Method Technical Manual, BRE Global Ltd Online. www.breeam.com/uknew-construction

[25] Sassi, P., Strategies for sustainable architecture, Taylor and Francis: New York, 2006.

[26] Wu, S. \& Noy, P., A conceptual design of a wireless sensor actuator system for optimizing energy and well-being in buildings. Intelligent Buildings International, 2(1), pp. 41-56, 2010.

[27] Jones, L., Environmentally responsible design: green and sustainable design for interior designers, John Wiley \& Sons: New Jersey, 2008.

[28] O’Neill, S. (2010) Microsoft's Home of the Future: A Visual Tour. Online. www.cio.com/article/597693/Microsoft s Home of the Future A Visua 1 Tour?page $=1$ \#slideshow

[29] Dounis, A.I., Tiropanis, P., Argiriou, A., \& Diamantis, A., Intelligent control system for reconciliation of the energy savings with comfort in buildings using soft computing techniques. Energy and Buildings, 43(1), pp. 66-74, 2011.

[30] Pandharipande, A. \& Caicedo, D., Daylight integrated illumination control of LED systems based on enhanced presence sensing. Energy and Buildings, 43(4), pp. 944-950, 2011.

[31] Llopa, M. \& Ponce-Alifonsoa, X., Identifying the role of final consumption in structural path analysis: An application to water uses. Ecological Economics, 109, pp. 203-210, 2015.

[32] Gan, X., Zuo, J., Ye, K., Skitmore, M. \& Xiong, B., Why sustainable construction? Why not? An owner's perspective. Habitat International, 47, pp. 61-68, 2015.

[33] Addington, D.M. \& Schodek, D.L., Smart materials and new technologies: for the architecture and design professions, Routledge: New York, 2005.

[34] Ruuska, A. \& Häkkinen, T., Material Efficiency of Building Construction. Buildings, 4(3), pp. 266-294, 2014.

[35] Schwartz, M. (ed). The Encyclopaedia of Smart Materials, John Wiley \& Sons: New Jersey, 2002. 